\title{
Dependence on Humidity and Aerosol Composition of the Gas-particle Partitioning of Weakly and Moderately Polar VOCs
}

\author{
Jeonghyeon Ahn ${ }^{\odot}$, Guiying Rao ${ }^{\circledR}$, Eric P. Vejerano*® \\ Center for Environmental Nanoscience and Risk, Department of Environmental Health Sciences, \\ University of South Carolina, Columbia, SC 29208, USA
}

\begin{abstract}
Volatile organic compounds (VOCs) dominate the class of pollutants that accumulate in the atmosphere and indoors. Assessing the gas-particle partitioning of VOCs is important to determine their fate, transport, and adverse health impacts. This work is a companion to our earlier study on the temperature dependence of VOC partitioning. Here, we report our measurement of the gas-particle partition coefficient $\left(K_{p}\right)$ for weakly polar (trichloroethylene, TCE) and moderately polar ( $n$-butanol, $n$-BuOH) VOCs under varying relative humidity $(\mathrm{RH})$ levels onto organic and inorganic aerosols. $K_{p}$ of TCE was four to five orders of magnitude lower than those of $n-\mathrm{BuOH}$. Results suggest preferential sorption of the VOCs onto inorganic aerosol particles than onto organic aerosol particles. $K_{p}$ values for both TCE and $n$ - $\mathrm{BuOH}$ decreased as RH levels increased; the $K_{p}$ for both VOCs declined sharply at an $\mathrm{RH}>35 \%$ onto inorganic aerosol particles, whereas the $K_{p}$ declined slowly onto organic aerosol particles. Partitioning of the VOCs onto organic aerosol particles was less dependent on $\mathrm{RH}$ levels while partitioning onto inorganic aerosol particles was important only at low $\mathrm{RH}$ levels. At lower $\mathrm{RH}$, partitioning proceeded by adsorbing onto the aerosol particles. In contrast, at higher $\mathrm{RH}$, the extremely low mass fraction of the VOCs, absorbed onto the aerosol particle's bulk by dissolving into the aqueous phase. For organic aerosol particles, partitioning may be dominated by adsorption at all $\mathrm{RH}$ levels. At increasing $\mathrm{RH}$ levels, both VOCs partitioning onto in/organic aerosol particles exhibited similar behavior (exponential) consistent to those observed for 1,2-dichlorobenzene, therefore, insensitive to the polarity. However, at a similar RH level, polarity affects the mass fraction of the VOCs that sorbed onto the aerosol particles.
\end{abstract}

Received: April 21, 2021

Revised: August 6, 2021

Accepted: August 27, 2021

${ }^{*}$ Corresponding Author:

filonchyk.mikalai@gmail.com

Keywords: Butanol, Trichloroethylene, Emission, Organics, Deliquescence, Adsorption, Absorption

\section{INTRODUCTION}

\section{Publisher:}

Taiwan Association for Aerosol Research

ISSN: $1680-8584$ print

ISSN: 2071-1409 online

Copyright: The Author(s). This is an open access article distributed under the terms of the Creative Commons Attribution License (CC BY 4.0), which permits unrestricted use, distribution, and reproduction in any medium, provided the original author and source are cited.

Volatile organic compounds (VOCs) dominate the class of organic pollutants that accumulate in the atmosphere and indoors due to their low boiling point and high vapor pressure. The contribution of biogenic VOC emission from South America, which is home to the largest rainforest forest in the world, accounts for $35 \%$ of the global isoprene emission alone (Guenther et al., 2012). In North America, while biogenic emissions dominate the VOC budget on a carbon basis, anthropogenic emissions comprise over half of the ambient VOC loading because of their longer aggregate lifetime (Chen et al., 2019). VOC emissions from mobile sources have declined. Still, those released from volatile chemical products (VCPs) have increased (McDonald et al., 2018). A primary sink of $\mathrm{VOC}$ is their chemical reactivity through multigenerational and multiphase reactions, converting VOCs to secondary atmospheric aerosol (SOA) (Donahue et al., 2007; Gong et al., 2018; Pan et al., 2009).

The gas-particle partitioning coefficient $\left(K_{p}\right)$ is a measure of a compound's ability to distribute between gas and aerosol phases; thus, it predicts the mobility and fate in the environment. Many 
studies on contaminants in aerosols have implicated semivolatile organic compounds (SVOCs) than do VOCs since the latter do not partition preferentially onto aerosols (Liang et al., 1997; Pankow, 1998; Goss and Schwarzenbach, 1999a; Qin et al., 2021; Wu et al., 2018). Although only a small fraction of a VOC will partition onto the gas phase, VOC concentration in the atmosphere and indoors substantially exceeds those of SVOCs (Xu and Little, 2006). Therefore, at a steadystate, for some VOCs, the mass fraction accumulated onto aerosol particles can reach similar orders to those of SVOCs (Hamilton et al., 2004; Matsumoto et al., 2010; Odabasi et al., 2005). Assessing VOCs' gas-particle partitioning is limited by the difficulty in determining the relatively small mass fraction in the aerosol to their high gas-phase concentration. Estimates of the partitioning coefficient of VOCs have been derived mainly from field sampling. $K_{p}$ acquired via field sampling can be inaccurate because of environmental and sampling factors that are difficult to control. Assessing VOCs' environmental and human health impact has been less understood because of the limited gas-particle partitioning data. To our knowledge, few studies have demonstrated the biological impact of aerosol-phase VOC. In this study, acrolein, an extremely volatile VOC, induces significant adverse biological effect on cells compared to the pristine aerosol (Ebersviller et al., 2012). This study suggests the need to understand more the biological impact of aerosol-bound VOCs. Exposure to VOCs via multiple routes induces short-term and long-term adverse health effects (Brown et al., 2015; Cakmak et al., 2014; Gao et al., 2014). Prenatal exposure to gas-phase VOCs negatively affects postnatal growth (Chang et al., 2017). Even more so, aerosol-bound VOCs can reach regions of the respiratory system that are typically inaccessible to gas-phase VOCs because they are poorly absorbed by cells (Ebersviller et al., 2012).

The uptake of VOCs on aerosol particles is affected by several factors. Foremost of these factors is the hygroscopic behavior and water content of aerosols. These factors are highly dependent on the chemical composition, mixing state, and $\mathrm{RH}$. Here, we focus on $\mathrm{RH}$ and aerosol composition. The interaction of aerosol components with their surroundings is complex; changes in one property influence other physicochemical behavior (Choi and Chan, 2002; Krieger et al., 2012; Martin, 2000). Uptake of water by the aerosol particles at different RH levels is a critical factor (Ding et al., 2021; Hennigan et al., 2009, 2008; Sun et al., 2013; Zhang et al., 2012). RH affects aerosol properties such as mass, size distribution, and composition (Hennigan et al., 2008; Zhang et al., 2012). Atmospheric aerosols of biogenic and anthropogenic origin are a mixture of complex inorganic and organic compounds with diverse physicochemical properties. Differences in composition drastically affect the partitioning behavior of a VOC on aerosol. Organic-phase water can significantly influence the total organic aerosol concentrations by increasing the aerosol mass depending on the relative humidity, particle size, and aerosol chemical composition (Jathar et al., 2016; Pye et al., 2017; Saxena et al., 1995). Often, studies account for the impact of inorganic aerosol but neglect the contribution of organic aerosols.

The organic fraction of atmospheric aerosol contains a large amount of water-soluble organic compounds (Decesari et al., 2005; Gysel et al., 2004; Saxena and Hildemann, 1996). Among the most abundant is succinic acid (Kawamura and Bikkina, 2016). Ammonium sulfate and succinic acid coexist in atmospheric aerosol (Lightstone et al., 2000; Liu et al., 2016). The presence of watersoluble organic acid (e.g., succinic acid) can modify the phase behavior or inorganic constituent, particularly those exhibiting distinct phase transition such as ammonium sulfate (Jing et al., 2018). The study outlined here focuses on aerosol with a single component (either organic or inorganic) rather than a mixture to benchmark each aerosol type's behavior under different RH levels. Although aerosols composed of a higher amount of inorganic component dictates water uptake, at an equal concentration (organic:inorganic), organic acids will influence water uptake behavior (Prenni et al., 2003). Hence, for predicting water uptake on aerosol with mixed composition, data from pure components can be used, assuming that each component contributes independently (Prenni et al., 2003).

Scant research was conducted on VOC partitioning onto airborne aerosol at different RH conditions. Many gas-particle partitioning studies have focused on SVOCs (Weschler and Nazaroff, 2010). SVOCs have been used as proxies in estimating the gas-particle partitioning of VOCs. However, SVOCs cannot accurately describe the VOC partitioning behavior because of the substantial differences in their physicochemical properties. Our previous study (accepted paper) investigated the partitioning behavior of 1,2-dichlorobenzene (1,2-DCB) and how temperature and $\mathrm{RH}$ affect partitioning. Using a previously developed method to measure the $K_{p}$ of moderately 
polar ( $n$-butanol, $n$-BuOH), weakly polar (trichloroethylene, TCE), and nonpolar (1,2-dichlorobenzene, 1,2-DCB). This study will help understand the transport, degradation, and health impact of airborne compounds via gas-to-particle partitioning.

\section{MATERIALS AND METHODS}

\subsection{Chemicals}

For this study, we used two VOCs: $n-\mathrm{BuOH}(\geq 99 \%)$ and TCE ( $\geq 99 \%)$, which were purchased from Sigma Aldrich and used without further purification. We choose TCE as a surrogate for nonpolar VOCs, whereas $n$-BuOH was selected as a surrogate for moderately polar compounds. Deuterated analogs of TCE (trichloroethylene- $d, \geq 98 \%$, Sigma-Aldrich, USA) and $n$-BuOH (1-butanol- $d_{10}, \geq 99 \%$, Sigma-Aldrich, USA) were used as the internal standards. All solutions were prepared in methanol (>99.99\%, Fisher Chemical). We generated the aerosols using dilute solutions of succinic acid ( $\geq 99 \%$, Alfa Aesar) and ammonium sulfate ( $\geq 99 \%$, Sigma). Hereafter, we will refer to aerosol particles of ammonium sulfate and succinic acid as Am Sulf and SA, respectively.

\subsection{Experimental Setup}

Detail of the experimental setup, characterization and verification of the total suspended particle (TSP), the analytical methods, and other important aspect of the experiment are described in our previous study (Ahn et al., 2021a). Briefly, we used a cylindrical chamber ( $\varnothing \sim 0.5 \mathrm{~m}, h \sim 0.1 \mathrm{~m}$, volume $\sim 7 \mathrm{~L}$ ) made of aluminum enclosed in a temperature-controlled cabinet (CEO932, Lunaire Environmental, New Columbia, PA) to maintain a constant temperature (Fig. 1). Three flows were directed to the chamber: dilute VOC, aerosol, and humid air flows. Dilute $n$-BuOH or TCE flow streams were generated by placing a 2-mL amber vial containing $1 \mathrm{~mL}$ of the pure VOC liquid in the chamber of a precision standard gas generator (491M-B, KIN-TEC Laboratories Inc, La Marque, TX, USA). Pure VOC vapor from the vial was diluted with clean, particle-free compressed air. The dilute TCE mixing ratio, or $n$ - $\mathrm{BuOH}$ mixing ratio, was $30 \mathrm{ppb}$ in air, which we used in all the tests in this study. We used a similar level for 1,2-DCB in our previous study. Mixing ratio was measured using a gas chromatograph-mass spectrometer (GC-MS) described in section 2.4. An $\mathrm{RH} /$ temperature probe (USBTENKI-T-RH-CC2, Dracal Technologies, Inc.) installed in the chamber measured the temperature and $\mathrm{RH}$ in real-time. To investigate the effect of $\mathrm{RH}$ on partitioning, we varied the $\mathrm{RH}$ level from $5 \%$ to $85 \%$, while we maintained the temperature at $25^{\circ} \mathrm{C}$. Detail of the experimental conditions is listed in Table 1.

The organic and inorganic aerosols were generated by atomizing a 200-ppm aqueous solution

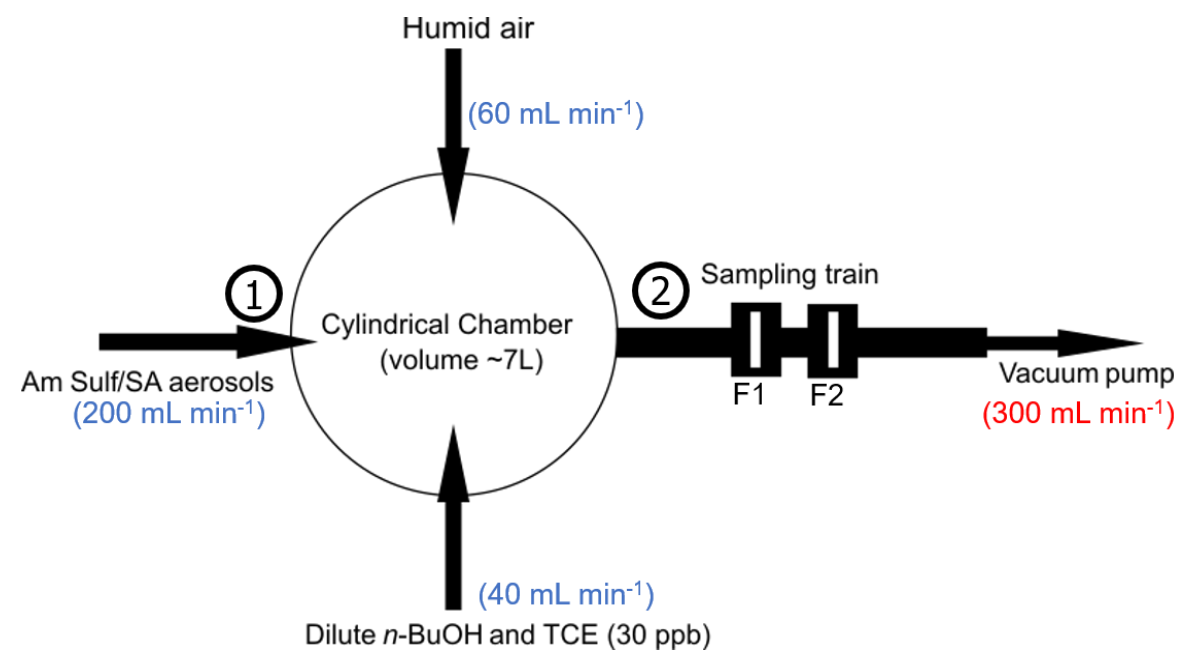

Fig. 1. The schematic of the experimental setup for measuring the gas-particle partitioning of surrogate VOCs. F1 and F2 are the filters. Location marked 1 and 2 are sites where measurement of aerosol properties was conducted. The schematic was adapted from our previous study (Ahn et al., 2021a). 
Table 1. RH levels for each compound and aerosol type used in this study.

\begin{tabular}{lllll}
\hline & TCE & & \multicolumn{2}{c}{$n$-BuOH } \\
\cline { 1 - 2 } \cline { 5 - 5 } Am Sulf & SA & Am Sulf & SA \\
\hline $5 \%$ & $5 \%$ & $5 \%$ & $5 \%$ \\
$35 \%$ & $40 \%$ & $35 \%$ & $35 \%$ \\
$55 \%$ & $60 \%$ & $65 \%$ & $70 \%$ \\
$85 \%$ & $85 \%$ & $80 \%$ & $85 \%$ \\
\hline
\end{tabular}

of ammonium sulfate and succinic acid. Ammonium sulfate salts and organic aerosol account for $>50 \%$ of the components of atmospheric aerosols (Cass et al., 2000). Ammonium sulfate is a representative of water-soluble inorganic salt, and succinic acid is a slightly water-soluble organic component in atmospheric aerosol (Abbatt et al., 2005; Riipinen et al., 2006). The atomizer's (TSI 3076, TSI Incorporated, Shoreview, MN) flow rate was set at $2.3 \mathrm{~L} \mathrm{~min}^{-1}$ using a mass flow controller (MFC, FC-280, Tylan). Aerosol exiting the atomizer was passed through a diffusion dryer containing silica beads. Silica beads were dried by heating them at $100^{\circ} \mathrm{C}$ before use for each sampling. The dried aerosol was routed to the chamber at a flow rate of $200 \mathrm{~mL} \mathrm{~min}^{-1}$, while the excess was vented into the atmosphere. Wet and dry air were mixed to achieve the required RH level. We set the VOC, humid air, and aerosol flow streams at 40,60 , and $200 \mathrm{~mL} \mathrm{~min}^{-1}$, respectively, resulting in a total flow rate of $300 \mathrm{~mL} \mathrm{~min}{ }^{-1}$ entering the chamber. Each flow rate was optimized to minimize VOC breakthrough during the sampling. The aerosol properties were measured using a scanning mobility particle sizer (SMPS, electrostatic classifier model 3082 with a condensation particle counter model 3775, TSI Incorporated, MN).

\subsection{Sampling and Analysis}

Two glass microfiber filters collected the aerosol containing the VOC (GF/F, ID, 13 mm; pore size, $1.0 \mu \mathrm{m}$, Whatman ${ }^{\mathrm{TM}}$ ) embedded in a separate filter holder connected in series. The sampling flow rate was set at $300 \mathrm{~mL} \mathrm{~min}^{-1}$ by an MFC with a vacuum pump (Model 6025SE-V, Environmental Monitoring System). The first filter captured the aerosol containing the sorbed VOC, whereas the second filter captured only the VOC. The second filter was used for correcting the VOC concentration in the gas phase that was collected on the filter fiber. Only a negligible amount of aerosol was captured in the second filter (Ahn et al., 2021a). After sampling, each filter was transferred to 10-mL borosilicate vials to achieve equilibrium between the headspace and aerosols on the filter. To collect the VOC in the headspace at equilibrium, we used solid-phase microextraction (SPME, Supelco ${ }^{\mathrm{TM}}$ ) using a needle assembled with a Carboxen ${ }^{\circledR} /$ Poly-dimethylsiloxane (CAR/PDMS) fiber $\left(\right.$ Supelco ${ }^{\mathrm{TM}}$ ), which was inserted and suspended in the headspace for $30 \mathrm{~min}$ and $4 \mathrm{~h}$ at $22^{\circ} \mathrm{C}$. The mass of VOC absorbed on SPME was injected into the GC-MS for quantitative analysis. Details of the sampling and characterization, such as the VOC recovery from the filter have been described previously (Ahn et al., 2021a). Each sampling and analysis were conducted in triplicate under similar condition.

Before each sampling, the VOC was introduced into the chamber for $3 \mathrm{~h}$ (total chamber outflow was $300 \mathrm{~mL} \mathrm{~min}^{-1}$ ) until the measured VOC concentration exiting the chamber was identical to that introduced. This result is consistent to the high relative recovery of VOCs from aluminum material (> 90\%) stored for $48 \mathrm{~h}$ (Kim et al., 2012), showing losses due to wall adsorption is minimal. Additionally, VOCs that sorbed on the wall equilibrated rapidly to those in the gas-phase (Shiraiwa and Seinfeld, 2012).

\subsection{VOC Analysis}

GC-MS (Clarus 680-Clarus SQ8T, PerkinElmer, Waltham, MA) system equipped with a DB-5 column (0.25 mm, internal diameter; $30 \mathrm{~m}$, length; $0.25 \mu \mathrm{m}$, film thickness) was used to analyze TCE and $n-\mathrm{BuOH}$. We used the following chromatographic condition and parameters: GC injector temperature $250^{\circ} \mathrm{C}$, split flow rate $20 \mathrm{~mL} \mathrm{~min}^{-1}$, carrier gas flow rate $1.1 \mathrm{~mL} \mathrm{~min}^{-1}$, and carrier gas helium (99.999\%). To separate TCE, we used the following GC setting: initial oven temperature $40^{\circ} \mathrm{C}$, hold time $0.5 \mathrm{~min}$, final temperature $100^{\circ} \mathrm{C}$, ramp rate $25^{\circ} \mathrm{C} \mathrm{min}{ }^{-1}$. For $n$-BuOH, we used the following setting for the first ramping: initial oven temperature $40^{\circ} \mathrm{C}$, hold time $0.1 \mathrm{~min}$, final temperature $60^{\circ} \mathrm{C}$, ramp rate $5^{\circ} \mathrm{C} \mathrm{min}-1$, hold time $0.1 \mathrm{~min}$. For the second ramping, the oven 
temperature was set to $140^{\circ} \mathrm{C}$, ramp rate $5^{\circ} \mathrm{C} \mathrm{min}-1$, and hold time $0.1 \mathrm{~min}$. The MS was operated under electron ionization mode at $70 \mathrm{eV}$. The spectra were acquired using selected ion monitoring. The temperature of the ion source and the transfer line were set as $200^{\circ} \mathrm{C}$. Mass-tocharge ratio $(\mathrm{m} / \mathrm{z})$ of 130 and 132 were used to identify TCE, and $\mathrm{m} / \mathrm{z}$ of 41 and 56 were used to identify $n-\mathrm{BuOH}$.

\section{$2.5 K_{p}$ Calculation}

The gas-particle partition coefficient, $K_{p}$, of VOCs on Am Sulf or SA aerosol particles were measured at $25^{\circ} \mathrm{C}$ and varying $\mathrm{RH}$ levels from 5 to $85 \%$. The $K_{p}$ values were calculated using the determined VOC concentration in the particle and gas phases using Eq. (1).

$K_{p}=\frac{[V O C]_{p}}{[V O C]_{g} \times T S P}$

where $[V O C]_{p}$ and $[V O C]_{g}$ are the VOC concentration in particle and air phases $\left(\mu \mathrm{g} \mathrm{m}^{-3}\right)$, and TSP denotes the mass concentration of the aerosols $\left(\mu \mathrm{g} \mathrm{m}^{-3}\right)$. We used a TSP level of $\sim 500 \mu \mathrm{g} \mathrm{m}^{-3}$. We used the TSP level recorded by the SMPS, which has been experimentally validated in our previous study (Ahn et al., 2021a).

\section{RESULTS}

\subsection{Effect of RH on $K_{p}$ of Weakly Polar and Strongly Polar VOCs}

Fig. 2 depicts the dependence of $K_{p}$ with $\mathrm{RH}$ at a constant temperature of $25^{\circ} \mathrm{C}$ for TCE and $n$-BuOH partitioning onto Am Sulf aerosols. The trendlines for the $K_{p}$ values for both organics decreased with increasing RH levels. For Am Sulf aerosol particles, the $K_{p}$ for both $n$-BuOH and TCE were highest at a low RH and declined continuously at higher RH levels. The $K_{p}$ values at an $\mathrm{RH}$ of $\sim 40 \%$ decreased sharply for Am Sulf aerosol particles. These behaviors were similar to that of 1,2-DCB. However, compared to 1,2-DCB partitioning onto the same aerosol particles, the decline in $K_{p}$ with RH was more gradual (Fig. 2). Compared to TCE and 1,2-DCB, the $K_{p}$ values were higher for $n$-BuOH, suggesting that it preferentially sorbed onto Am Sulf aerosol particles.

Fig. 3 depicts the dependence of $K_{p}$ with $\mathrm{RH}$ at a constant temperature of $25^{\circ} \mathrm{C}$ for TCE and $n$-BuOH partitioning onto SA aerosol particles. Compared to the partitioning of these organics onto Am Sulf aerosol particles, the $K_{p}$ decline slowly with increasing RH levels. At all RH levels, the $K_{p}$ varied only within an interval of $\sim 5 \times 10^{-13}$ for TCE (Fig. 3(a)) and $\sim 10 \times 10^{-13}$ for 1,2-DCB. The most extensive interval range was for $n-\mathrm{BuOH}$, which fluctuated by an interval of $\sim 20 \times 10^{-13}$. However, compared to 1,2-DCB partitioning onto the same aerosol composition, $K_{p}$ 's decline with $\mathrm{RH}$ was more gradual. The $K_{p} \mathrm{~s}$ for $n-\mathrm{BuOH}$ were higher than those for TCE and 1,2-DCB (Figs. 2 and 3), consistent with their observed behavior on Am Sulf, suggesting preferential sorption.

Overall, the $K_{p}$ s for the three VOCs partitioning into Am Sulf aerosol particles were higher than
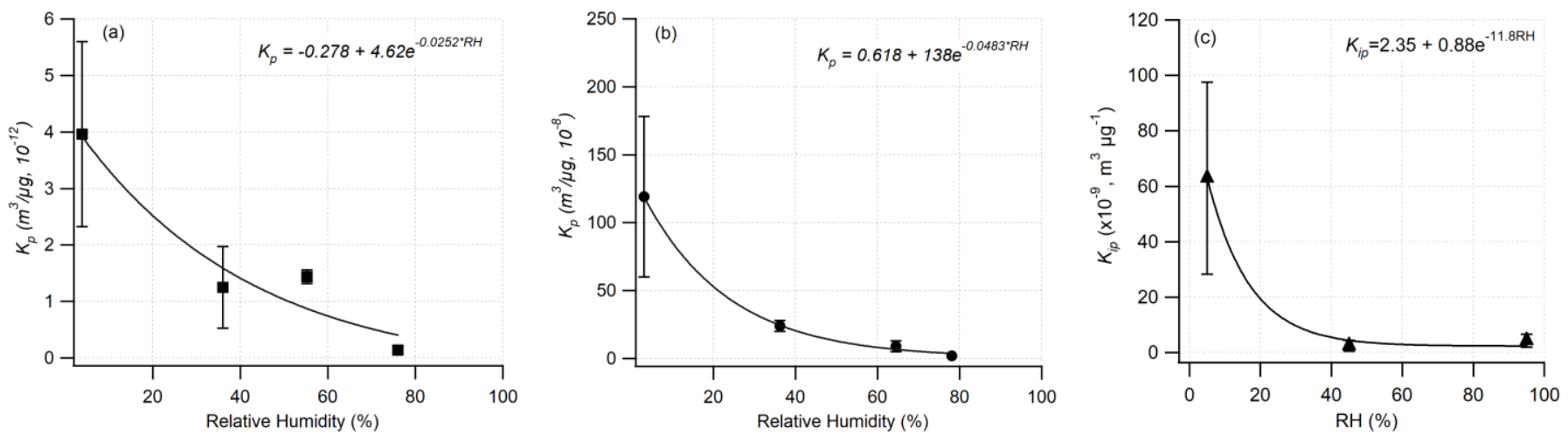

Fig. 2. The $K_{p}$ of (a) TCE, (b) $n-\mathrm{BuOH}$, and (c) 1,2-DCB (Ahn et al., 2021a) partitioning into Am Sulf aerosol at $25^{\circ} \mathrm{C}$ at different RHs. Error bars are one standard deviation from the mean, which were taken from triplicate measurements. 

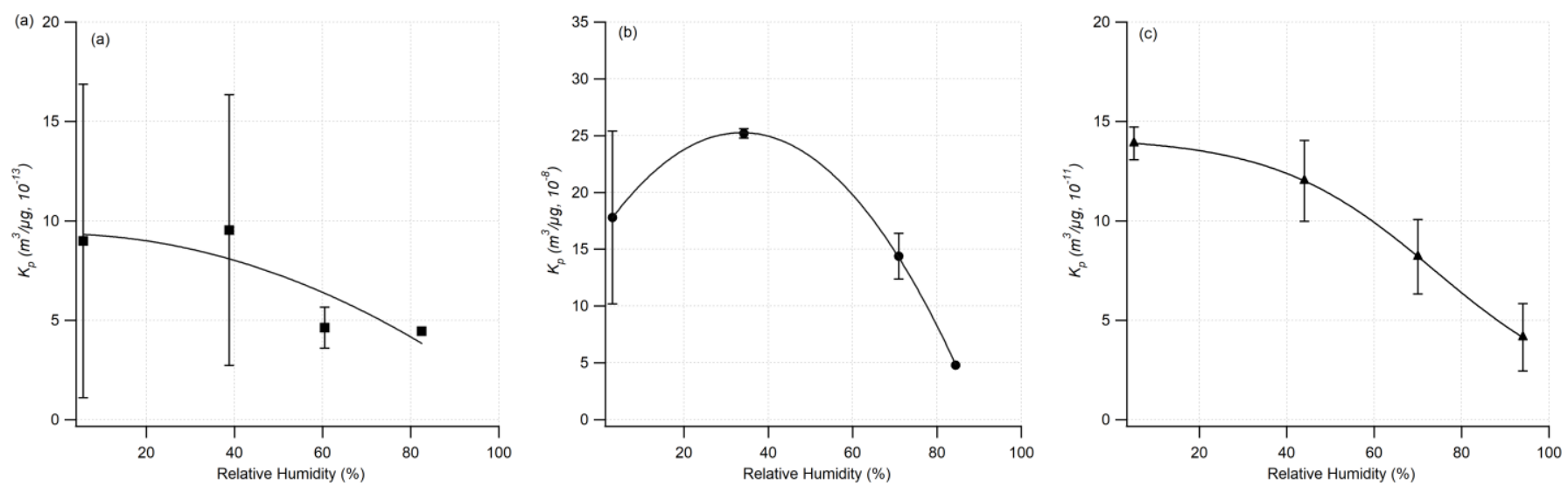

Fig. 3. The $K_{p}$ of (a) TCE and (b) $n-\mathrm{BuOH}$, and (c) 1,2-DCB (Ahn et al., 2021a) partitioning into SA aerosol at $25^{\circ} \mathrm{C}$. Error bars are one standard deviation from the mean, which were taken from triplicate measurements. Solid lines are not fit but were drawn as a guide only.

those onto SA aerosol particles. In general, the $K_{p}$ for TCE, $n$-BuOH, and 1,2-DCB partitioning onto Am Sulf aerosol particles were $\sim 5 \times, \sim 10 \times$, and $\sim 600 \times$ higher than onto SA aerosol particles. As the $K_{p}$ of Am Sulf aerosol were $1.36 \times 10^{-13}$ to $3.96 \times 10^{-12}$ for TCE and $1.57 \times 10^{-8}$ to $1.19 \times 10^{-6}$ for $n-\mathrm{BuOH}$, the $K_{p}$ of $n-\mathrm{BuOH}$ was four orders of magnitude higher than those for TCE. For the partitioning onto SA aerosol particles, the $K_{p}$ were $4.45 \times 10^{-13}$ to $8.99 \times 10^{-13}$ for TCE and $4.80 \times$ $10^{-8}$ to $1.78 \times 10^{-7}$ for $n-\mathrm{BuOH}$. The $K_{p}$ of $n-\mathrm{BuOH}$ was five orders of magnitude higher than those of TCE.

\subsection{Evolution in Aerosol Properties at Different RH Levels}

We monitored changes in the properties of Am Sulf and SA aerosols for $\sim 8 \mathrm{~h}$ at different RH levels (Fig. 4). The particle median diameter appeared to be less affected by RH even at higher $\mathrm{RH}$ levels. The size of SA aerosol particles was slightly larger than those of Am Sulf aerosol particles; average particle median diameter was $95 \pm 7 \mathrm{~nm}$ for Am Sulf aerosol particles and 108 $\pm 12 \mathrm{~nm}$ for SA aerosol particles. For both aerosol types, we observed that the TSP and particle number concentration fluctuated more at an $\mathrm{RH}$ of $\sim 85 \%$ but were stable at lower $\mathrm{RH}$ during the 8-h monitoring. The particle number concentrations for Am Sulf aerosol were $5.37 \times 10^{6} \mathrm{~cm}^{-3}$ at an $\mathrm{RH}$ of $5 \% \mathrm{RH}, 5.65 \times 10^{6} \mathrm{~cm}^{-3}$ at $35 \% \mathrm{RH}, 5.48 \times 10^{6} \mathrm{~cm}^{-3}$ at $65 \% \mathrm{RH}$, and $5.52 \times 10^{6} \mathrm{~cm}^{-3}$ at $85 \% \mathrm{RH}$. Although the particle number concentration as depicted in Fig. 4 fluctuated the concentration remained within $10^{6} \mathrm{~cm}^{-3}$, except at an $\mathrm{RH}$ of $85 \%$, which increased by an order of magnitude. Particle number concentrations of SA aerosol particles were $5.56 \times 10^{6} \mathrm{~cm}^{-3}, 6.24 \times$ $10^{6} \mathrm{~cm}^{-3}, 5.86 \times 10^{6} \mathrm{~cm}^{-3}$, and $9.90 \times 10^{6} \mathrm{~cm}^{-3}$ at RH levels of $5 \%, 35 \%, 65 \%$, and $85 \%$, respectively. At an $\mathrm{RH}$ of $85 \%$, the number concentration for Am Sulf aerosol particles fluctuated intensely but stabilized after $4 \mathrm{~h}$ and resulted to higher TSP compared to those at lower RH levels. At similar $\mathrm{RH}$ level, the number concentration for SA aerosol particles also fluctuated for $4 \mathrm{~h}$, but the TSPs were within a similar level to those measured at lower RH levels. Higher fluctuations in TSP only occurred for Am Sulf aerosol. We did not observe intense fluctuations of the TSP for SA aerosol. The TSPs measured by the SMPS were at similar levels for Am Sulf and SA aerosols, which were $1,930 \pm 461$ and $1,952 \pm 715 \mu \mathrm{g} \mathrm{m}^{-3}$, respectively. Note that the high uncertainty was due to the strong fluctuations at an $\mathrm{RH}$ of $\sim 85 \%$. TSP and particle number concentration became slightly larger during the 8-h measurement at all $\mathrm{RH}$ levels.

\section{DISCUSSION}

Although the mass fraction of VOCs that partitions into aerosol particles is less compared to SVOCs, VOCs dominate the class of atmospheric and indoor pollutants. Therefore, some highly abundant VOC can reach concentration levels comparable to SVOCs with very low abundance (Hamilton et al., 2004; Matsumoto et al., 2010; Odabasi et al., 2005). This companion paper 
Am Sulf
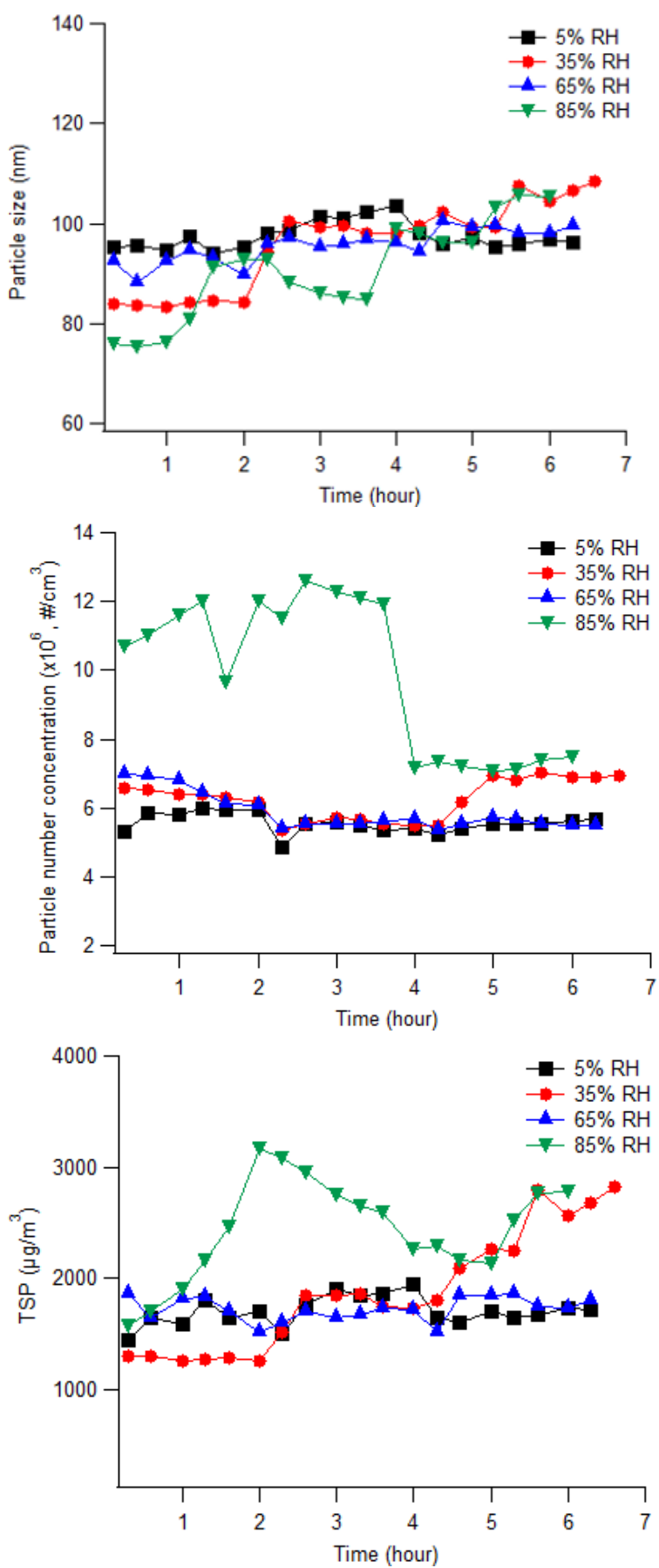

SA
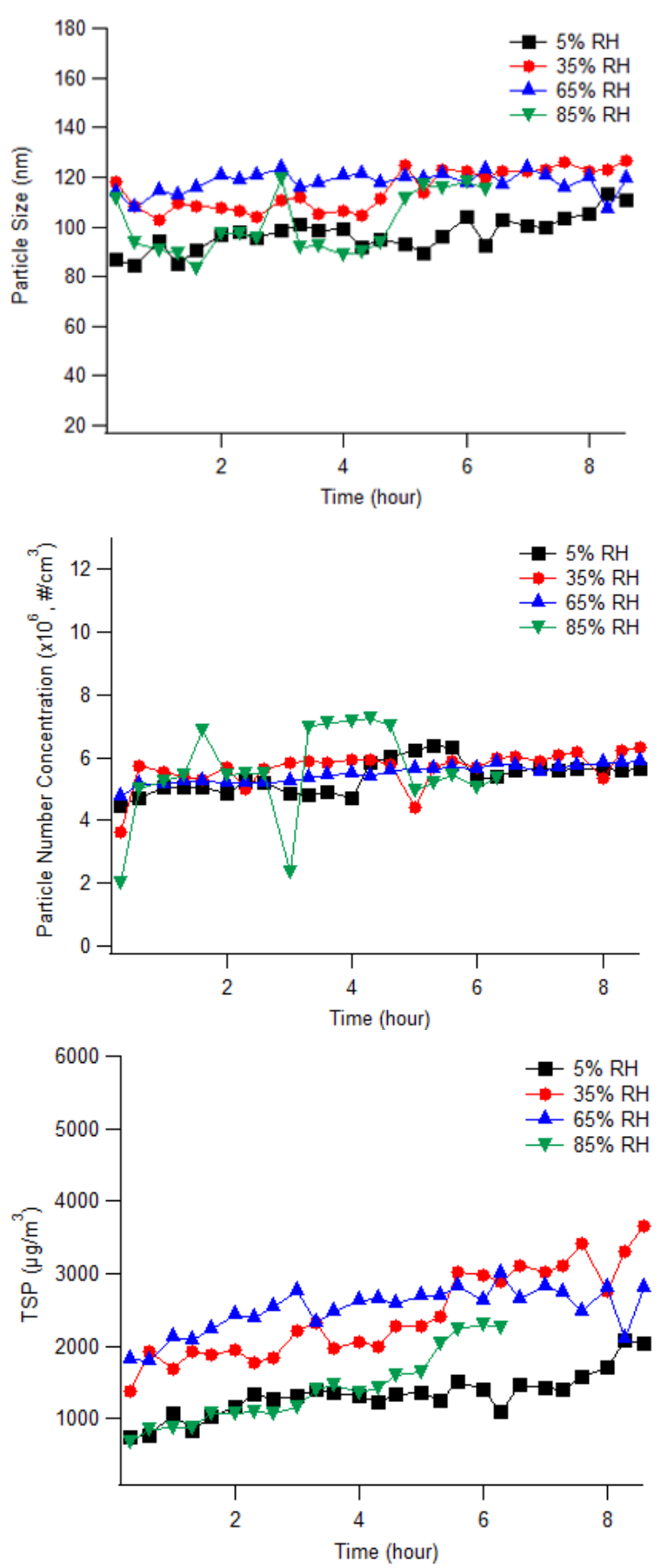

Fig. 4. Time-evolution of the particle size, particle number concentration, and TSP of Am Sulf and SA aerosols at different RH levels.

described our measurement of the partitioning coefficient for TCE and $n$-BuOH under different $\mathrm{RH}$ levels and aerosol composition. We compared them with our earlier studies on 1,2-DCB (Ahn et al., 2021a). The $K_{p}$ values for TCE and $n-\mathrm{BuOH}$ were at similar ranges to those measured for different aerosols sampled from diverse sources (Arp et al., 2008) and were at similar orders to that of 1,2-DCB (Ahn et al., 2021a). Overall, results showed that: (1) VOC partitioning onto Am Sulf was higher than onto SA aerosol particles; (2) partitioning on SA was affected less at all RH levels, whereas partitioning onto Am Sulf aerosol particles was affected only at low RH level. 


\subsection{Partitioning Mechanism}

Gas-particle partitioning of organics can proceed via absorption (i.e., diffusion into the bulk of the aerosol) and adsorption (i.e., interacts with the active surface sites) (Pankow, 1994). Although the dominant partitioning mechanisms are unclear, it is well known that environmental conditions (Goss and Schwarzenbach, 1998), more importantly, RH and temperature, and aerosol composition modulate these processes. However, the effects of $\mathrm{RH}$ are tightly coupled with the surface chemistry of the particles (Sobanska et al., 2015). In general, partitioning of the VOCs onto Am Sulf was likely via adsorption at an $\mathrm{RH}<40 \%$, whereas above this $\mathrm{RH}$, the partitioning was more plausibly via absorption. VOC partitioning onto SA aerosols appears to proceed via adsorption at all RH levels, perhaps except at saturated $\mathrm{RH}$ since dried SA aerosol only deliquesces at an $\mathrm{RH} \sim 99 \%$ (Bilde and Svenningsson, 2004). Our earlier paper described the effects of temperature $\left(5-35^{\circ} \mathrm{C}\right.$ ) for the partitioning of TCE and $n$-BuOH (Ahn et al., 2021b). Partitioning of TCE is independent of temperature as deemed from the constant enthalpy of desorption consistent with the classic v'ant Hoff relationship (In $K_{p}$ vs. 1/T). However, partitioning of $n$ - BuOH strongly depends on temperature, resulting in a non-linear behavior (Ahn et al., 2021b). At a constant $\mathrm{RH}$, but increasing temperature, absolute humidity increases; under such conditions, $n$-BuOH forms various complexes with water (DeJaco et al., 2016) with different desorption enthalpies (Ahn et al., 2021b).

\subsection{Effect of RH}

Although the fit uses at most four data points, similar to that for 1,2-DCB (Ahn et al., 2021a), the partitioning of TCE and $n$-BuOH onto Am Sulf aerosol followed an exponential relationship between $K_{p}$ and $\mathrm{RH}$ in which $\ln K_{p}=-\mathrm{C} \times R H+\mathrm{E}$, where $\mathrm{C}$ and $\mathrm{E}$ are VOC- and aerosol-specific constants) (Goss, 1992; Goss and Eisenreich, 1997). For the three VOCs we studied, regardless of the polarity, $\mathrm{RH}$ has a negligible impact above $50 \%$, consistent with those reported in the literature (Arp et al., 2008; Cotham and Bidleman, 1992; Jathar et al., 2016). The results for TCE and $n-\mathrm{BuOH}$, and that with our previous study with 1,2-DCB, suggest that aerosol-specific properties strongly affect partitioning behavior than do VOC-specific properties. The overall $K_{p}$ values of TCE and $n$-BuOH decreased as the $\mathrm{RH}$ increased for organic and inorganic aerosols at $25^{\circ} \mathrm{C}$. However, sorption of the VOCs onto SA aerosol regardless of their polarity did not fit the exponential dependence of $K_{p}$ with $\mathrm{RH}$. This result suggests that partitioning behavior is driven more by aerosol-specific properties than do the VOCs' properties; under such a mechanism, it appears that the VOC's polarity has less impact on partitioning.

\subsection{Effect of Water Uptake}

Absorption of water has a considerable impact on partitioning. At high $\mathrm{RH}$, water vapor can compete with the adsorption sites on the aerosol. At $\mathrm{RH}$ levels of 50 to $70 \%$, the liquid water content of atmospheric aerosols accounts for $\sim 10 \%$ of the total particulate mass and increases significantly at RH > 70\% (Pilinis et al., 1989; Thibodeaux et al., 1991). For instance, organic-phase water can increase the aerosol mass, providing a larger absorbing matrix for organics (Jathar et al., 2016). Am Sulf aerosol particles deliquesce at high RH ( 82\%) (Brooks et al., 2002) and highly hygroscopic. Still, even under low RH, uptake of water can cover active sites on the aerosol particles, which will decrease the mass fraction of adsorbed organics onto the aerosol. On Am Sulf aerosol particles, partitioning is dominated primarily by the aerosol particle's higher active surface sites at low RH (adsorption) (Goss and Schwarzenbach, 1999b). On SA, water covering the active sites was less pronounced because SA is less hygroscopic than Am Sulf. Therefore, the number of active sites remained almost constant, which may explain the slow decline in $K_{p}$ (Fig. 3(b)) as the RH increased. For SA aerosol particles, the dissolution of the VOCs in the aerosol water was not likely the mechanism because SA deliquesces at a high RH (Bilde and Svenningsson 2004). SA droplets do not deliquesce even at $90 \% \mathrm{RH}$ as deemed from a single-droplet study at $25^{\circ} \mathrm{C}$ (Peng et al., 2001). Smaller particles of SA have a higher deliquescence RH (DRH) of 99\% (Bilde and Svenningsson, 2004). Moreover, the growth factor of SA (RH of $10 \%$ and $90 \%$ ) was $\sim 1$, suggesting that they are not hygroscopic within this RH range (Peng et al., 2001). Therefore, below saturated $\mathrm{RH}$, dry SA aerosol particles introduced into the chamber was not expected to grow. However, in Fig. 4, we observed a slight change in the particle median diameter as the RH increased (Hämeri et al., 2000). It is known that small soluble and insoluble particles increase in 
size well below the DRH because of the adsorption of water onto their surfaces (Hämeri et al., 2000). The lesser effect of RH on the $K_{p}$ of the VOCs partitioning onto SA is consistent with these observations. For small Am Sulf particles, DRH is influenced by two effects. First, the solubility of a crystal increases as its size decreases, lowering the DRH. Particles smaller than $100 \mathrm{~nm}$ have a DRH of 79.9\% (Tang and Munkelwitz, 1993). Even submicron particles of pure AS have a DRH = $80.7 \pm 0.2 \%$ (Laskina et al., 2015; Liu et al., 2016; Wang et al., 2017). Small SA particles $<200 \mathrm{~nm}$ require overcoming an energy barrier to uptake water (Brooks et al., 2002; Wex et al., 2007). Second, when the particles deliquesce, water vapor pressure increases, increasing the DRH (Hämeri et al., 2000). Aerosols consisting of mixed components have significantly different DRH than aerosol consisting of single solute, such as this study. Aerosol consisting of a mixture of salts effloresces at $15-40 \% \mathrm{RH}$, crystalizes simultaneously, and deliquesces at $63.6 \%$ (Tang and Munkelwitz, 1993; Wu et al., 2019). Thus, for a mixed aerosol, the partitioning behavior will differ from an aerosol consisting of one solute.

\subsection{Effect of the VOC's Physicochemical Properties}

We observed that moderately polar, weakly polar, and nonpolar aromatic VOCs have similar behavior on Am Sulf aerosol particles as shown by their trendlines in Fig. 2. However, the nature of the organics (for instance, polarity and solubility) dictates the VOC's mass fraction that will sorb onto aerosol particles. Below the DRH, aerosol particles can absorb sufficient amount of water. Hence, to some extent, the aerosol particle's surface is covered with water layers, in which the VOCs can dissolve. At higher RHs ( $\geq 35 \%$ ), the VOCs partitioned onto Am Sulf by dissolving into the aqueous phase. The amount of the VOCs that partitioned into the aerosol particles was inconsistent with the trend in water solubility of the VOCs. Although to some extent, compounds with high water solubility such as $n-\mathrm{BuOH}$ (66x higher than TCE) had a higher mass fraction partitioned onto both aerosols. However, solubility alone does not dictate mass transfer of a VOC onto aerosols. The solubility of the $1,2-\mathrm{DCB}, \mathrm{TCE}$, and $n-\mathrm{BuOH}$ at $25^{\circ} \mathrm{C}$ were $1.56,11.8$, and $680 \mathrm{wt} \%$, respectively. Whereas, in general, the $K_{p}$ of $1,2-\mathrm{DCB}, \mathrm{TCE}$, and $n-\mathrm{BuOH}$ at $25^{\circ} \mathrm{C}$ were on the order of $10^{-11}, 10^{-13}$, and $10^{-8}$, respectively (He et al., 2010). The saturated vapor pressure, dimensionless Henry's law constant $\left(H_{L}\right)$, and octanol-air partition coefficient $\left(K_{o a}\right)$ (Table 2$)$ of the VOCs did not result in a consistent trend with $K_{p}$. For VOCs, $K_{o a}$ is not applicable compared to their use for predicting $K_{p}$ of SVOCs. The relationship of $K_{p}$ with increasing RH (i.e., being exponential) is identical for the three VOCs regardless of their polarity. However, at a similar RH level, the mass fraction that will sorb onto the aerosol particles is to some extent influenced by the VOC's polarity and their capacity to interact with the aerosol particles' active sites.

\subsection{VOC/Aerosol Interactions}

In general, for both aerosol types, we ascribed the larger $K_{p}$ at an RH $10 \%$, to Van der Waals interaction between the VOC and the aerosol particles' surface. TCE, a weakly polar compound, interacts strongly with the surface of Am Sulf aerosol particles via Van der Waal's interaction (Schwarzenbach et al., 2016), as deemed from the higher partitioning constant compared to those of SA aerosol particles. We observed a similar behavior with the other two VOCs as well. For real atmospheric aerosol consisting of hydrophobic components, this observation is applicable since nonpolar and weakly polar VOCs are less affected at RH levels of 50-90\% because they preferentially partition into that phase (Cotham and Bidleman 1992; Jathar et al., 2016). At low RH, TCE interacts with molecular layers of water (Goss and Schwarzenbach, 1999b), on the surface of Am Sulf aerosol via Van der Waal's interaction. Despite the relatively higher solubility

Table 2. Experimental and selected literature physicochemical properties of the VOCs

\begin{tabular}{llllll}
\hline VOC & $\begin{array}{l}\text { Experimental } \\
\log K_{\mathrm{p}}\end{array}$ & $\begin{array}{l}\text { Solubility } \\
(\mathrm{wt} \%)\end{array}$ & $\begin{array}{l}\text { Vapor Pressure } \\
(\text { Torr })\end{array}$ & $\begin{array}{l}\text { Dimensionless Henry's } \\
\text { Law Constant }\left(\mathrm{H}_{\mathrm{L}}\right)\end{array}$ & $\begin{array}{l}\text { Octanol-air Partition } \\
\text { Coefficient (Koa) }\end{array}$ \\
\hline $1,2-\mathrm{DCB}$ & -11 & 1.56 & 1.36 & $7.8 \times 10^{-2}$ & 4.36 \\
TCE & -13 & 11.2 & 69 & $4.2 \times 10^{-1}$ & 2.99 \\
$n$-BUOH & -8 & 680 & 7 & $3.6 \times 10^{-4}$ & 4.19 \\
\hline
\end{tabular}

Data were taken from the National Institute of Standards and Technology except the experimental log $K_{p}$. 
of TCE in water to that of 1,2-DCB, the levels were similar because TCE is weakly polar and can interact with the water in the aerosol particles better by Van der Waals interaction. However, between the two types of aerosols, Van der Waals interaction of TCE with SA aerosol particles is weaker compared with Am Sulf aerosol particles.

The faster decline in the $K_{p}$ values even at a lower RH for Am Sulf aerosol particles is due to water film (Goss and Schwarzenbach, 1999b) covering the aerosol particles. Once the aerosol particle is covered with water the number of active sites available for the adsorption of the VOCs is reduced. At high $\mathrm{RH}$, water solvates and ionizes Am Sulf aerosol. Dissolved ions interacted strongly with water, which reduced VOC uptake onto Am Sulf aerosol particles. The small mass fraction that partitioned onto the aerosol particles occurred via dissolution, the extent of which depends on the VOC's properties. However, deactivation of these sites due to water was less intense for SA aerosol particles since they deliquesce only at saturated RH. Moreover, SA aerosol particles are less hygroscopic than Am Sulf aerosol particles. Thus, at almost all RH levels, the partitioning of TCE and $n$-BuOH on SA primarily occurred via adsorption on the aerosol particle's surface via Van der Waals interactions (Goss, 1993; Schwarzenbach et al., 2016). Of the three VOCs, $n$ - $\mathrm{BuOH}$ had the highest $K_{p}$. This behavior is expected since $n$-BuOH can form a strong hydrogen bond with the adsorbed molecular water layer on Am Sulf or SA aerosols and with the carboxyl groups in SA. At high $\mathrm{RH}$, water vapor competes strongly with $n$-BuOH for the available sorption sites on the aerosol particle's surface resulting in a slight decline in $K_{p}$.

Since we used a simple model aerosol, the interaction does not account for the complexity of aerosol systems. Ambient atmospheric aerosols contain multiple components that are susceptible to phase separate depending on the condition-more importantly- $\mathrm{RH}$. Phase separation can induce the aerosol to form various structures (Freedman, 2020, 2017; You et al., 2012). The formation of such structures and multiphase systems may interact with VOC differently. Hence, a model aerosol we used in this experiment will substantially exhibit drastically different partitioning behavior.

Only limited studies have assessed the health impacts of aerosol-bound VOCs, partly because of the limited data on their partitioning. VOCs' contribution in aerosol particles is often excluded in inhalation exposure assessment because it is assumed that their amount in aerosol particles is negligible. However, aerosol- and VOC-specific properties and environmental conditions affect partitioning. Thus, chronic exposure to aerosol-bound VOCs may be a significant concern depending on the VOC type and the prevailing environmental condition (e.g., $\mathrm{RH}$, temperature). For example, formaldehyde is more polar and water-soluble despite being highly volatile relative to the VOCs we investigated in this study. Such a VOC class may amplify our inhalation risk because of the high mass partitioning onto aerosol particles. Our experimentally derived $K_{p}$, when coupled with particulate matter (PM) concentration data in cities worldwide and the PM fractions deposited into the different regions of the respiratory system, can be used to calculate the regional mass deposition for some VOCs. These data can be used for assessing risk and improve our knowledge of the human health impacts of aerosol-bound VOCs.

\section{CONCLUSIONS}

Many contaminants of concern in the environment are VOCs, which may be released into the environment from chemical spills, use and disposal of chemicals, and other activities. VOCs are subject to transfer between media. Partition coefficients are critical for predicting the fate and transport of VOCs in the environment and assessing exposure to them. In general, partitioning of the VOCs onto Am Sulf aerosol particles was likely via adsorption at an $\mathrm{RH}<40 \%$, whereas above this $\mathrm{RH}$, the small amount detected on the aerosol potentially partitioned via absorption. On Am Sulf aerosol particles, partitioning proceeds via by adsorption due to the aerosol's higher active surface sites at low RH. It appears that aerosol-specific properties strongly affect partitioning behavior than do VOC-specific properties. For TCE, a weakly polar compound, interacted strongly with the surface of Am Sulf aerosol particles via Van der Waal's interaction, as deemed from the higher partitioning constant compared to those of SA aerosol particles. The faster decline in the $K_{p}$ values even at a lower $\mathrm{RH}$ for Am Sulf aerosol particles is due to water film covering the surface and is more hygroscopic than SA aerosol particles. Deactivation of active sites by water was less intense for SA aerosol particles because they deliquesce only at nearly saturated RH. $n$-BuOH had 
the highest $K_{p}$, which we attribute to its ability to form strong hydrogen bond with the adsorbed molecular water layer on both aerosols. These studies were conducted on simple model aerosols. Future studies should investigate more complex aerosols as aerosol-specific properties appear to dictate partitioning. We expect that a more complex aerosols would behave substantially different from our model aerosols. These experimental gas-particle partitioning data can be used for developing VOC-specific models. Results can be used to improve the prediction of the impacts of VOCs on health and the environment.

\section{CONFLICTS OF INTEREST}

We declare we have no conflicts of interest.

\section{DISCLAIMER}

Reference to any companies or specific commercial products does not constitute endorsement by the authors.

\section{ACKNOWLEDGEMENT}

We thank the US Army Research Office (GRANT11970168) for providing financial support.

\section{REFERENCES}

Abbatt, J.P.D., Broekhuizen, K., Pradeep Kumar, P. (2005). Cloud condensation nucleus activity of internally mixed ammonium sulfate/organic acid aerosol particles. Atmos. Environ. 39, 47674778. https://doi.org/10.1016/j.atmosenv.2005.04.029

Ahn, J., Rao, G., Vejerano, E. (2021a). Partitioning of 1,2-dichlorobenzene onto organic and inorganic aerosols. Environ Chem. 18, 61-70. https://doi.org/10.1071/EN21016

Ahn, J., Rao, G., Vejerano, E. (2021b). Temperature dependence of the gas-particle partitioning of selected VOCs. Environ. Sci. Processes Impacts 23, 947-955. https://doi.org/10.1039/D1EM 00176K

Arp, H.P.H., Schwarzenbach, R.P., Goss, K.U, (2008). Ambient gas/particle partitioning. 1. Sorption mechanisms of apolar, polar, and ionizable organic compounds. Environ. Sci. Technol. 42, 5541-5547. https://doi.org/10.1021/es703094u

Bilde, M., Svenningsson, B. (2004). CCN activation of slightly soluble organics: The importance of small amounts of inorganic salt and particle phase. Tellus B 56, 128-134. https://doi.org/10.34 02/tellusb.v56i2.16406

Brooks, S.D., Wise, M.E., Cushing, M., Tolbert, M.A. (2002). Deliquescence behavior of organic/ammonium sulfate aerosol. Geophys. Res. Lett. 29, 23-1-23-24. https://doi.org/10.10 29/2002GL014733

Brown, D.R., Lewis, C., Weinberger, B.I. (2015). Human exposure to unconventional natural gas development: A public health demonstration of periodic high exposure to chemical mixtures in ambient air. J. Environ. Sci. Health., Part A 50, 460-472. https://doi.org/10.1080/10934529. 2015.992663

Cakmak, S., Dales, R.E., Liu, L., Kauri, L.M., Lemieux, C.L., Hebbern, C., Zhu, J. (2014). Residential exposure to volatile organic compounds and lung function: Results from a population-based cross-sectional survey. Environ. Pollut. 194, 145-151. https://doi.org/10.1016/j.envpol.2014.0 7.020

Cass, G.R., Hughes, L.A., Bhave, P., Kleeman, M.J., Allen, J.O., Salmon, L.G. (2000). The chemical composition of atmospheric ultrafine particles. Philos. Trans. R. Soc. London, Ser. A 358, 25812592. https://doi.org/10.1098/rsta.2000.0670

Chang, M., Park, H., Ha, M., Hong, Y.C., Lim, Y.H., Kim, Y., Kim, Y.J., Lee, D., Ha, E.H. (2017). The effect of prenatal TVOC exposure on birth and infantile weight: The Mothers and Children's Environmental Health study. Pediatr. Res. 82, 423. https://doi.org/10.1038/pr.2017.55 
Chen, X., Millet, D.B., Singh, H.B., Wisthaler, A., Apel, E.C., Atlas, E.L., Blake, D.R., Bourgeois, I., Brown, S.S., Crounse, J.D., de Gouw, J.A., Flocke, F.M., Fried, A., Heikes, B.G., Hornbrook, R.S., Mikoviny, T., Min, K.E., Müller, M., Neuman, J.A., O'Sullivan, D.W., et al. (2019). On the sources and sinks of atmospheric VOCs: An integrated analysis of recent aircraft campaigns over North America. Atmos. Chem. Phys. 19, 9097-9123. https://doi.org/10.5194/acp-19-9097-2019

Choi, M.Y., Chan, C.K. (2002). The effects of organic species on the hygroscopic behaviors of inorganic aerosols. Environ. Sci. Technol. 36, 2422-2428. https://doi.org/10.1021/es0113293

Cotham, W.E., Bidleman, T.F. (1992). Laboratory investigations of the partitioning of organochlorine compounds between the gas phase and atmospheric aerosols on glass fiber filters. Environ. Sci. Technol. 26, 469-478. https://doi.org/10.1021/es00027a003

Decesari, S., Facchini, M.C., Fuzzi, S., McFiggans, G.B., Coe, H., Bower, K.N. (2005). The watersoluble organic component of size-segregated aerosol, cloud water and wet depositions from Jeju Island during ACE-Asia. Atmos. Environ. 39, 211-222. https://doi.org/10.1016/j.atmosenv. 2004.09.049

Ding, J., Dai, Q., Zhang, Y., Xu, J., Huangfu, Y., Feng, Y. (2021). Air humidity affects secondary aerosol formation in different pathways. Sci. Total Environ. 759, 143540. https://doi.org/10.10 16/j.scitotenv.2020.143540

Donahue, N.M., Tischuk, J.E., Marquis, B.J., Hartz, K.E.H. (2007). Secondary organic aerosol from limona ketone: Insights into terpene ozonolysis via synthesis of key intermediates. Phys. Chem. Chem. Phys. 9, 2991-2998. https://doi.org/10.1039/B701333G

Ebersviller, S., Lichtveld, K., Sexton, K.G., Zavala, J., Lin, Y.H., Jaspers, I., Jeffries, H.E. (2012). Gaseous VOCs rapidly modify particulate matter and its biological effects - Part 1: Simple VOCs and model PM. Atmos. Chem. Phys. Discuss. 12, 5065-5105. https://doi.org/10.5194/acpd-12 5065-2012

Freedman, M.A. (2017). Phase separation in organic aerosol. Chem. Soc. Rev. 46, 7694-7705. https://doi.org/10.1039/C6CS00783J

Freedman, M.A. (2020). Liquid-liquid phase separation in supermicrometer and submicrometer aerosol particles. Acc. Chem. Res. 53, 1102-1110. https://doi.org/10.1021/acs.accounts.0c00093

Gao, Y., Zhang, Y., Kamijima, M., Sakai, K., Khalequzzaman, M., Nakajima, T., Shi, R., Wang, X., Chen, D., Ji, X. (2014). Quantitative assessments of indoor air pollution and the risk of childhood acute leukemia in Shanghai. Environ. Pollut. 187, 81-89. https://doi.org/10.1016/j.envpol.2013.12.029

Gong, Y., Chen, Z., Li, H. (2018). The oxidation regime and SOA composition in limonene ozonolysis: Roles of different double bonds, radicals, and water. Atmos. Chem. Phys. 18, 15105-15123. https://doi.org/10.5194/acp-18-15105-2018

Goss, K.U. (1992). Effects of temperature and relative humidity on the sorption of organic vapors on quartz sand. Environ. Sci. Technol. 26, 2287-2294. https://doi.org/10.1021/es00035a030

Goss, K.U. (1993). Effects of temperature and relative humidity on the sorption of organic vapors on clay minerals. Environ. Sci. Technol. 27, 2127-2132. https://doi.org/10.1021/es00047a019

Goss, K.U., Eisenreich, S.J. (1997). Sorption of volatile organic compounds to particles from a combustion source at different temperatures and relative humidities. Atmos. Environ. 31, 2827-2834. https://doi.org/10.1016/S1352-2310(97)00048-4

Goss, K.U., Schwarzenbach, R.P. (1999a). Quantification of the effect of humidity on the gas/mineral oxide and gas/salt adsorption of organic compounds. Environ. Sci. Technol. 33, 4073-4078. https://doi.org/10.1021/es990502g

Goss, K.U., Schwarzenbach, R.P. (1999b). Quantification of the effect of humidity on the gas/mineral oxide and gas/salt adsorption of organic compounds. Environ. Sci. Technol. 33, 4073-4078. https://doi.org/10.1021/es990502g

Guenther, A.B., Jiang, X., Heald, C.L., Sakulyanontvittaya, T., Duhl, T., Emmons, L.K., Wang, X. (2012). The Model of Emissions of Gases and Aerosols from Nature version 2.1 (MEGAN2.1): an extended and updated framework for modeling biogenic emissions. Geosci. Model Dev. 5 , 1471-1492. https://doi.org/10.5194/gmd-5-1471-2012

Gysel, M., Weingartner, E., Nyeki, S., Paulsen, D., Baltensperger, U., Galambos, I., Kiss, G. (2004). Hygroscopic properties of water-soluble matter and humic-like organics in atmospheric fine aerosol. Atmos. Chem. Phys. 4, 35-50. https://doi.org/10.5194/acp-4-35-2004

Hämeri, K., Väkevä, M., Hansson, H.C., Laaksonen, A. (2000). Hygroscopic growth of ultrafine ammonium sulphate aerosol measured using an ultrafine tandem differential mobility 
analyzer. J. Geophys. Res. 105, 22231-22242. https://doi.org/10.1029/2000JD900220

Hamilton, J.F., Webb, P.J., Lewis, A.C., Hopkins, J.R., Smith, S., Davy, P. (2004). Partially oxidised organic components in urban aerosol using GCXGC-TOF/MS. Atmos. Chem. Phys. 4, 12791290. https://doi.org/10.5194/acp-4-1279-2004

He, Y., Jain, P., Yalkowsky, S.H. (2010). Handbook of aqueous solubility data. CRC press.

Hennigan, C.J., Bergin, M.H., Dibb, J.E., Weber, R.J. (2008). Enhanced secondary organic aerosol formation due to water uptake by fine particles. Geophys. Res. Lett. 35, L18801. https://doi.org/10.1029/2008GL035046

Hennigan, C.J., Bergin, M.H., Russell, A.G., Nenes, A., Weber, R.J. (2009). Gas/particle partitioning of water-soluble organic aerosol in Atlanta. Atmos. Chem. Phys. 9, 3613-3628. https://doi.org/ 10.5194/acp-9-3613-2009

Jathar, S.H., Mahmud, A., Barsanti, K.C., Asher, W.E., Pankow, J.F., Kleeman, M.J. (2016). Water uptake by organic aerosol and its influence on gas/particle partitioning of secondary organic aerosol in the United States. Atmos. Environ. 129, 142-154. https://doi.org/10.1016/j.atmose nv.2016.01.001

Jing, B., Wang, Z., Tan, F., Guo, Y., Tong, S., Wang, W., Zhang, Y., Ge, M. (2018). Hygroscopic behavior of atmospheric aerosols containing nitrate salts and water-soluble organic acids. Atmos. Chem. Phys. 18, 5115-5127. https://doi.org/10.5194/acp-18-5115-2018

Kawamura, K., Bikkina, S. (2016). A review of dicarboxylic acids and related compounds in atmospheric aerosols: Molecular distributions, sources and transformation. Atmos. Res. 170, 140-160. https://doi.org/10.1016/j.atmosres.2015.11.018

Kim, Y.H., Kim, K.H., Jo, S.H., Jeon, E.C., Sohn, J.R., Parker, D.B. (2012). Comparison of storage stability of odorous VOCs in polyester aluminum and polyvinyl fluoride Tedlar ${ }^{\circledR}$ bags. Anal. Chim. Acta 712, 162-167. https://doi.org/10.1016/j.aca.2011.11.014

Krieger, U.K., Marcolli, C., Reid, J.P. (2012). Exploring the complexity of aerosol particle properties and processes using single particle techniques. Chem. Soc. Rev. 41, 6631-6662. https://doi.org/ 10.1039/C2CS35082C

Laskina, O., Morris, H.S., Grandquist, J.R., Qin, Z., Stone, E.A., Tivanski, A.V., Grassian, V.H. (2015). Size matters in the water uptake and hygroscopic growth of atmospherically relevant multicomponent aerosol particles. J. Phys. Chem. A 119, 4489-4497. https://doi.org/10.1021/jp510268p

Liang, C., Pankow, J.F., Odum, J.R., Seinfeld, J.H. (1997). Gas/particle partitioning of semivolatile organic compounds to model inorganic, organic, and ambient smog aerosols. Environ. Sci. Technol. 31, 3086-3092. https://doi.org/10.1021/es9702529

Lightstone, J.M., Onasch, T.B., Imre, D., Oatis, S. (2000). Deliquescence, efflorescence, and water activity in ammonium nitrate and mixed ammonium nitrate/succinic acid microparticles. J. Phys. Chem. A 104, 9337-9346. https://doi.org/10.1021/jp002137h

Liu, Q., Jing, B., Peng, C., Tong, S., Wang, W., Ge, M. (2016). Hygroscopicity of internally mixed multi-component aerosol particles of atmospheric relevance. Atmos. Environ. 125, 69-77. https://doi.org/10.1016/j.atmosenv.2015.11.003

Martin, S.T. (2000). Phase transitions of aqueous atmospheric particles. Chem. Rev. 100, 34033454. https://doi.org/10.1021/cr990034t

Matsumoto, K., Matsumoto, K., Mizuno, R., Igawa, M. (2010). Volatile organic compounds in ambient aerosols. Atmos. Res. 97, 124-128. https://doi.org/10.1016/j.atmosres.2010.03.014

McDonald, B.C., de Gouw, J.A., Gilman, J.B., Jathar, S.H., Akherati, A., Cappa, C.D., Jimenez, J.L., Lee-Taylor, J., Hayes, P.L., McKeen, S.A., Cui, Y.Y., Kim, S.W., Gentner, D.R., Isaacman-VanWertz, G., Goldstein, A.H., Harley, R.A., Frost, G.J., Roberts, J.M., Ryerson, T.B., Trainer, M. (2018). Volatile chemical products emerging as largest petrochemical source of urban organic emissions. Science 359, 760-764. https://doi.org/10.1126/science.aaq0524

Odabasi, M., Ongan, O., Cetin, E. (2005). Quantitative analysis of volatile organic compounds (VOCs) in atmospheric particles. Atmos. Environ. 39, 3763-3770. https://doi.org/10.1016/j.at mosenv.2005.02.048

Pan, X., Underwood, J.S., Xing, J.H., Mang, S.A., Nizkorodov, S.A. (2009). Photodegradation of secondary organic aerosol generated from limonene oxidation by ozone studied with chemical ionization mass spectrometry. Atmos. Chem. Phys. 9, 3851-3865. https://doi.org/10.5194/acp9-3851-2009

Pankow, J.F. (1994). An absorption model of the gas/aerosol partitioning involved in the formation 
of secondary organic aerosol. Atmos. Environ. 28, 189-193. https://doi.org/10.1016/13522310(94)90094-9

Pankow, J.F. (1998). Further discussion of the octanol/air partition coefficient Koa as a correlating parameter for gas/particle partitioning coefficients. Atmos. Environ. 32, 1493-1497. https://doi.org/10.1016/S1352-2310(97)00383-X

Peng, C., Chan, M.N., Chan, C.K. (2001). The hygroscopic properties of dicarboxylic and multifunctional acids: Measurements and UNIFAC predictions. Environ. Sci. Technol. 35, 44954501. https://doi.org/10.1021/es0107531

Pilinis, C., Seinfeld, J.H., Grosjean, D. (1989). Water content of atmospheric aerosols. Atmos. Environ. 23, 1601-1606. https://doi.org/10.1016/0004-6981(89)90419-8

Prenni, A.J., DeMott, P.J., Kreidenweis, S.M. (2003). Water uptake of internally mixed particles containing ammonium sulfate and dicarboxylic acids. Atmos. Environ. 37, 4243-4251. https://doi.org/10.1016/S1352-2310(03)00559-4

Pye, H.O.T., Murphy, B.N., Xu, L., Ng, N.L., Carlton, A.G., Guo, H., Weber, R., Vasilakos, P., Appel, K.W., Budisulistiorini, S.H., Surratt, J.D., Nenes, A., Hu, W., Jimenez, J.L., Isaacman-VanWertz, G., Misztal, P.K., Goldstein, A.H. (2017). On the implications of aerosol liquid water and phase separation for organic aerosol mass. Atmos. Chem. Phys. 17, 343-369. https://doi.org/10.519 4/acp-17-343-2017

Qin, M., Yang, P.F., Hu, P.T., Hao, S., Macdonald, R.W., Li, Y.F. (2021). Particle/gas partitioning for semi-volatile organic compounds (SVOCs) in level III multimedia fugacity models: Both gaseous and particulate emissions. Sci. Total Environ. 790, 148012. https://doi.org/10.1016/j.scitotenv. 2021.148012

Riipinen, I., Svenningsson, B., Bilde, M., Gaman, A., Lehtinen, K.E.J., Kulmala, M. (2006). A method for determining thermophysical properties of organic material in aqueous solutions: Succinic acid. Atmos. Res. 82, 579-590. https://doi.org/10.1016/j.atmosres.2006.02.014

Saxena, P., Hildemann, L.M., McMurry, P.H., Seinfeld, J.H. (1995). Organics alter hygroscopic behavior of atmospheric particles. J. Geophys. Res. 100, 18755-18770. https://doi.org/10.102 9/95JD01835

Saxena, P., Hildemann, L.M. (1996). Water-soluble organics in atmospheric particles: A critical review of the literature and application of thermodynamics to identify candidate compounds. J. Atmos. Chem. 24, 57-109. https://doi.org/10.1007/BF00053823

Schwarzenbach, R.P., Gschwend, P.M., Imboden, D.M. (2016. Environmental organic chemistry. John Wiley \& Sons.

Shiraiwa, M., Seinfeld, J.H. (2012). Equilibration timescale of atmospheric secondary organic aerosol partitioning. Geophys. Res. Lett. 39, L24801. https://doi.org/10.1029/2012GL054008

Sobanska, S., Barbillat, J., Moreau, M., Nuns, N., De Waele, I., Petitprez, D., Tobon, Y., Bremard, C. (2015). Influence of stearic acid coating of the $\mathrm{NaCl}$ surface on the reactivity with $\mathrm{NO}_{2}$ under humidity. Phys. Chem. Chem. Phys. 17, 10963-10977. https://doi.org/10.1039/C4CP05655H

Sun, Y., Wang, Z., Fu, P., Jiang, Q., Yang, T., Li, J., Ge, X. (2013). The impact of relative humidity on aerosol composition and evolution processes during wintertime in Beijing, China. Atmos. Environ. 77, 927-934. https://doi.org/10.1016/j.atmosenv.2013.06.019

Tang, I.N., Munkelwitz, H.R. (1993). Composition and temperature dependence of the deliquescence properties of hygroscopic aerosols. Atmos. Environ. 27, 467-473. https://doi.org/ 10.1016/0960-1686(93)90204-C

Thibodeaux, L.J., Nadler, K.C., Valsaraj, K.T., Reible, D.D. (1991). The effect of moisture on volatile organic chemical gas-to-particle partitioning with atmospheric aerosols-competitive adsorption theory predictions. Atmos. Environ. 25, 1649-1656. https://doi.org/10.1016/0960-1686(91)9 0023-Z

Wang, X., Jing, B., Tan, F., Ma, J., Zhang, Y., Ge, M. (2017). Hygroscopic behavior and chemical composition evolution of internally mixed aerosols composed of oxalic acid and ammonium sulfate. Atmos. Chem. Phys. 17, 12797-12812. https://doi.org/10.5194/acp-17-12797-2017

Weschler, C.J., Nazaroff, W.W. (2010). SVOC partitioning between the gas phase and settled dust indoors. Atmos. Environ. 44, 3609-3620. https://doi.org/10.1016/j.atmosenv.2010.06.029

Wex, H., Ziese, M., Kiselev, A., Henning, S., Stratmann, F. (2007). Deliquescence and hygroscopic growth of succinic acid particles measured with LACIS. Geophys. Res. Lett. 34, L17810. https://doi.org/10.1029/2007GL030185 
Wu, L., Li, X., Ro, C.U. (2019). Hygroscopic behavior of ammonium sulfate, ammonium nitrate, and their mixture particles. Asian J. Atmos. Environ. 13, 196-211. https://doi.org/10.5572/aj ae.2019.13.3.196

Wu, Y., Eichler, C.M.A., Cao, J., Benning, J., Olson, A., Chen, S., Liu, C., Vejerano, E.P., Marr, L.C., Little, J.C. (2018). Particle/gas partitioning of phthalates to organic and inorganic airborne particles in the indoor environment. Environ. Sci. Technol. 52, 3583-3590. https://doi.org/10.1 021/acs.est.7b05982

$\mathrm{Xu}$, Y., Little, J.C. (2006). Predicting emissions of SVOCs from polymeric materials and their interaction with airborne particles. Environ. Sci. Technol. 40, 456-461. https://doi.org/10.102 1/es051517j

You, Y., Renbaum-Wolff, L., Carreras-Sospedra, M., Hanna, S.J., Hiranuma, N., Kamal, S., Smith, M.L., Zhang, X., Weber, R.J., Shilling, J.E., Dabdub, D., Martin, S.T., Bertram, A.K. (2012). Images reveal that atmospheric particles can undergo liquid-liquid phase separations. Proc. Natl. Acad. Sci. U.S.A. 109, 13188-13193. https://doi.org/10.1073/pnas.1206414109

Zhang, X., Liu, J., Parker, E.T., Hayes, P.L., Jimenez, J.L., Gouw, J.A. de, Flynn, J.H., Grossberg, N., Lefer, B.L., Weber, R.J. (2012). On the gas-particle partitioning of soluble organic aerosol in two urban atmospheres with contrasting emissions: 1. Bulk water-soluble organic carbon. J. Geophys. Res. 117, D00V16. https://doi.org/10.1029/2012JD017908 